\title{
Metodologias e Estratégias Pedagógicas utilizadas por Educadores de uma Universidade Aberta à Terceira Idade
}

\author{
Meire Cachioni' \\ Tiago Nascimento Ordonez' \\ Samila Sathler Tavares Batistoni' \\ Thaís Bento Lima-Silva' \\ 'Universidade de São Paulo (USP), São Paulo/SP - Brasil
}

RESUMO - Metodologias e Estratégias Pedagógicas utilizadas por Educadores de uma Universidade Aberta à Terceira Idade. O estudo buscou caracterizar as estratégias pedagógicas utilizadas nas atividades educativas em um programa de educação permanente para idosos. O estudo é de caráter exploratório-descritivo, com participação de 82 professores/monitores. As emissões referentes ao que facilita a aprendizagem da pessoa idosa geraram três grupos de respostas: Categoria 1. Pedagogia Participativa Problematizadora; Categoria 2. Estratégias cognitivas considerando os declínios associados à idade; Categoria 3. Pedagogia da Transmissão. Concluiu-se que durante o processo educacional, deve-se encorajar uma apropriação ativa e crítica, em vez do acúmulo estático de conhecimento por parte das pessoas idosas.

Palavras-chave: Estratégias Pedagógicas. Docentes. Universidade Aberta à Terceira Idade.

\begin{abstract}
Methodologies and Pedagogical Strategies used by Educators of a University of the Third Age. This study aimed to characterize the pedagogical strategies used in educational activities on a continuing education program for seniors. It is an exploratory and descriptive study with the participation of 82 teachers/instructors. The responses related to what facilitates learning of the elderly have generated three groups of responses: Category 1. Problematizing Participant Pedagogy; Category 2. Cognitive strategies considering the declines associated with age; Category 3 . Pedagogy of Transmission. It was concluded that during the educational process, an active and critical appropriation must be encouraged, instead of the static accumulation of knowledge on the part of the elderly.

Keywords: Teaching Strategies. Teachers. University of the Third Age.
\end{abstract}

Educação \& Realidade, Porto Alegre, v. 40, n. 1, p. 81-103, jan./mar. 2015. 
Metodologias e Estratégias Pedagógicas utilizadas por Educadores...

\section{Introdução}

A primeira experiência brasileira de educação para idosos foi implementada pelo Serviço Social do Comércio (SESC) de São Paulo -, sob influência francesa. Na década de 1960 essa organização fundou os primeiros Grupos de Convivência e, na década de 1970, as primeiras Escolas Abertas para a Terceira Idade. Ofereciam informações sobre o envelhecimento, programas de preparação para aposentadoria, atualização cultural e atividades físicas, de expressão e de lazer. Sustentados numa proposta de educação permanente, buscavam o desenvolvimento de potencialidades, de novos projetos de vida e estimulavam a participação ativa do idoso na família e na comunidade.

No entanto, no contexto dos programas educativos destinados a pessoas idosas, as Universidades Abertas à Terceira Idade (UnATIs) destacam-se pela manutenção da educabilidade dos idosos, da oportunidade de fortes interações sociais e da promoção da qualidade de vida. Além da convivência, o pensar, o fazer e o aprender favorecem o bem-estar (Cachioni, 2012).

As UnATIs inserem-se no conceito de educação permanente, proposto pela UNESCO, de que o aprendizado deve estar presente ao longo de toda a vida, de forma constante, interativa e cumulativa para acompanhar as mudanças rápidas e contínuas da sociedade contemporânea (Cachioni; Palma, 2006).

A Universidade de Ciências Sociais de Toulouse, França, no início da década de 1970, foi berço da primeira Universidade da Terceira Idade (The University Of The Third Age U3A). A partir dessa iniciativa local, o movimento UnATI se espalhou por todo o mundo de tal forma que hoje milhões de pessoas idosas, de diversos países, de diferentes continentes, participam de uma série de atividades intelectuais e culturais, que contribuem para um envelhecimento ativo e, consequentemente, para uma velhice bem-sucedida (Cachioni; Ordonez, 2011).

No Brasil, as primeiras ações seguidas pelo modelo UnATI foram no âmbito da extensão universitária na área gerontológica e datam do início da década de 1980, com expressiva expansão na década de 1990, em todo o território nacional.

Em levantamento realizado em 2004, Cachioni localizou cerca de 200 programas nas instituições de ensino superior brasileiras, sendo que a maior parte estava concentrada no estado de São Paulo. Em universidades públicas ou privadas, os programas objetivam dar conta de fornecer oportunidades de compensação e enriquecimento cognitivo, integração e reconhecimento social, de satisfação e de envolvimento às coortes mais velhas (Cachioni; Aguilar, 2008).

A literatura internacional sobre Universidades da Terceira Idade relata os modelos e características dos programas e de sua clientela. Poucas referências são feitas aos docentes envolvidos nesses progra- 
mas, no que se refere a sua experiência, formação gerontológica e estratégias de ensino. Em artigo publicado por Swindell (2009), escrito a partir da compilação de informações promovida pelos autores junto a Universidades da Terceira Idade em vários países do mundo, encontramos alguns dados sobre os docentes. Na Grã-Bretanha, na Austrália e Estados Unidos, as atividades são geralmente conduzidas por professores voluntários e existe uma certa carência de professores com formação superior. Na França, na Bélgica e na Suíça, em Portugal e na Holanda, o corpo docente é formado de educadores universitários, remunerados e preocupados em manter um rigoroso padrão acadêmico de ensino. Na Alemanha, a preocupação central dos docentes é desenvolver programas e métodos de ensino especiais, adaptados às necessidades dos idosos. Na China, os programas são disputados por professores com alto nível de formação acadêmica. No Uruguai parece haver grande preocupação em relação à formação de seus docentes e à metodologia por eles utilizada nas atividades que são desenvolvidas.

No Brasil, raras são as referências ao docente. Não possuímos uma área definida para a sua formação, ela tem estado a cargo de poucos cursos de atualização oferecidos nas próprias Universidades da Terceira Idade, dos núcleos de estudos gerontológicos na universidade e dos cursos de especialização em gerontologia.

O primeiro relato sobre procedimentos metodológicos e formação profissional de professores de um programa de Universidade da Terceira Idade, está presente na dissertação de Alves (1997) A autora nota que os professores são indicados pelos departamentos da universidade, independentemente de terem formação específica na área gerontológica. A questão pedagógica é apontada como algo preocupante - “[...] a pura transposição dos chamados métodos e tecnologias de ensino usados nos cursos de graduação, pós-graduação ou do $1^{\circ}$ e $2^{\circ}$ graus é inadequada para a terceira idade" (Alves, 1997, p. 68). Essa afirmação foi reforçada por um levantamento realizado para que se detectassem os motivos de evasão, no qual 16,5\% dos alunos apontaram, como falha do curso, aulas monótonas ou extensas e inadequação do material didático utilizado pelos professores. Um grupo de alunas apontou como pontos negativos do programa "[...] a falta de preparo por parte de alguns docentes em atuar com a terceira idade, pois desenvolvem uma metodologia própria para os alunos da graduação, não tendo uma metodologia específica para alunos idosos" (Alves, 1997, p. 80).

Outro fator importante que envolve a prática docente é o que diz respeito à formação oferecida pelos programas universitários aos seus alunos maduros e idosos. Poderíamos levantar questões sobre: que tipo de formação está sendo oferecida? Em que suportes teóricos e metodológicos se apoia essa formação?

Fazendo referência às peculiaridades e diversidades do coletivo dos idosos, Martinez (1998) destaca que a formação que se desenvolve nas Universidades da Terceira Idade deve partir das necessidades su- 
Metodologias e Estratégias Pedagógicas utilizadas por Educadores...

geridas pelos próprios idosos, sob pena de ser pouco significativa para eles. Assim, os programas de formação universitária para idosos devem partir de um levantamento de suas necessidades. Os alunos devem ser parceiros na elaboração desses programas. Ainda que apoiados no princípio da educação permanente - o homem aprende desde que nasce até que morre -, o que caracteriza a busca desses cursos pelos adultos maduros e idosos é a fruição, o gosto por aprender, a realização de sonhos e projetos de vida adiados, a necessidade de se sentir vivo, ativo, atualizado e inserido na sua comunidade. Esse aluno não deve fazer nada a que seja obrigado, deve poder escolher seu horário, seu professor e suas atividades. Deve poder buscar seu crescimento pessoal e coletivo.

Sáez e Escarjabal (1998) propõe uma educação menos disciplinar, menos acadêmica e mais associada às necessidades identificadas pelos idosos, com a ajuda dos profissionais da área. Nesses territórios de intervenção, parece mais apropriado contar com uma pedagogia mais participativa e ativa montada sobre um edifício teórico fundamental, medular, sobre o qual podem se apoiar intervenções educativas que sejam programadas e executadas por meio de atividades de diferentes tipos, avaliadas durante e depois de sua realização.

Segundo Giubilei (1993), é muito comum no campo da educação a tentativa de transplantar os conhecimentos que se tem das características da criança e do adolescente para a compreensão da personalidade do adulto. E é justamente aqui que se dão os grandes impactos, não só para o adulto que se vê muitas vezes incompreendido, como para o educador que geralmente não consegue alcançar suas metas de trabalho.

Escarbajal (2009) possui ideias semelhantes às de Giubilei. Para o autor, é um lamentável erro considerar a educação de idosos nas mesmas perspectivas utilizadas em outras etapas da vida. Os programas educacionais para a terceira idade devem ter como ponto de partida conhecimentos específicos sobre as características dessa clientela, que possui peculiaridades garantidas pelo seu próprio desenvolvimento e experiências acumuladas, que lhes confere autonomia para decidir quando, como e o que desejam aprender.

Segundo Clavijo (1999), para qualquer atividade desenvolvida num programa universitário para idosos, são fundamentais três aspectos:

1. $\mathrm{O}$ aspecto humano: o professor e o aluno - a aprendizagem deve concentrar-se no educando, conduzida por ele; o professor tem o papel de facilitador. A atenção dos educadores deve fazer-se de modo a proporcionar uma relação educativa, democrática, pluralista e participativa que sugere a dicotomia professor-aluno, eliminando a tendência tradicional de que o professor seja o eixo central do processo educativo e o aluno relegado à situação de mero receptor.

2. O paradigma didático: a aula deve ser um lugar de encontro, de interação social e intercâmbio de experiências, para a construção de um conhecimento que possa ser socialmente compartilhado.

84 Educação \& Realidade, Porto Alegre, v. 40, n. 1, p. 81-103, jan./mar. 2015 Disponível em: <http://www.ufrgs.br/edu_realidade> 
3. Conceitualização da aprendizagem: deve ser significativa - os novos conhecimentos precisam ter um valor prático e relevante para a vida do aluno idoso. Uma das razões pelas quais os adultos continuam aprendendo com eficácia é que concentram sua aprendizagem nas áreas de experiência de seu interesse. Portanto, impulsiona-se uma motivação fundamental - a vontade de aprender - como principal auxiliar da aprendizagem, além do que pessoas que se mantêm em atividade nas tarefas intelectuais conservam essa capacidade ao longo de sua vida.

Palma (2000) apresenta a educação permanente como norteadora da proposta pedagógica de programas para idosos. Adota a metodologia participativa problematizadora, sugerida por Bordenave (1983), como referencial para a prática docente. Segundo a autora, numa proposta pedagógica de educação permanente direcionada a adultos maduros e idosos, mas que pode abranger todas as idades, os envolvidos são o investigador-educador e o educando-ator, coparticipantes no processo de indagar e refletir acerca de sua própria realidade para descrevê-la e explicá-la, gerar conhecimento e atuar sobre ela. Isso porque, à medida que o homem reflete sobre o seu contexto e responde aos seus desafios, ele se compromete, cria cultura, constrói a si mesmo e se torna sujeito.

Devido à heterogeneidade de necessidades, motivações e interesses existentes nos grupos de idosos, gerada pela particularidade das histórias e trajetórias de vida, devem ocorrer investimentos na criação e no aprimoramento de uma metodologia para o trabalho educacional, que valorize as experiências acumuladas e que torne o aluno idoso um agente de seu próprio aprendizado. Os professores serão profissionais de diversas áreas do conhecimento e profissões que deverão desenvolver competências específicas, disposições afetivas e características pessoais que favoreçam a sua atuação, no sentido de beneficiar os idosos e a sociedade formada de pessoas de todas as idades.

O presente estudo justifica-se pela grande diversidade das características das universidades abertas à terceira idade, uma vez que cada instituição toma as próprias decisões sobre objetivos, conteúdos, estrutura curricular, atividades e corpo docente. Tais programas atuam a partir de seus recursos humanos próprios, e de sua ideologia sobre velhice e sobre educação na velhice. Não é comum aos programas uma ampla discussão e divulgação sobre seus procedimentos pedagógicos, uma vez que o leque de atividades é extremamente diversificado. Objetivou-se caracterizar as estratégias pedagógicas utilizadas por professores que desenvolvem atividades educativas oferecidas em um programa de educação permanente para pessoas idosas. Adicionalmente descrever o perfil sociodemográfico e educacional (idade, sexo, curso de graduação a que pertence, ano que está cursando, área de formação superior dos docentes, tempo de atuação e experiência anterior de trabalho com idosos) dos professores responsáveis e monitores discentes da graduação de uma universidade aberta à terceira idade; identificar o

Educação \& Realidade, Porto Alegre, v. 40, n. 1, p. 81-103, jan./mar. 2015

Disponível em: <http://www.ufrgs.br/edu_realidade> 
Metodologias e Estratégias Pedagógicas utilizadas por Educadores...

tipo de atividade que desenvolvem no programa; identificar a prevalência das metodologias e estratégias pedagógicas utilizadas, identificar os recursos didáticos usados em aula; avaliar a percepção dos professores responsáveis e monitores sobre o que facilita o aprendizado dos alunos-idosos.

\section{Métodos e Materiais}

Trata-se de um estudo de caráter exploratório-descritivo com análise quantitativa dos dados.

O presente estudo, conforme classificação apresentada por Gil (1999), configura-se como uma pesquisa exploratória, uma vez que o conhecimento sobre metodologias e estratégias educacionais utilizadas em universidades abertas à terceira idade é extremamente incipiente. $\mathrm{O}$ caráter exploratório permitirá trazer à luz conhecimentos do ensino desenvolvido em um importante programa de educação não-formal, muito utilizado por pessoas idosas, mas pouco explorado cientificamente.

Para atingir os objetivos propostos, a abordagem da pesquisa é descritiva. Serão verificadas as relações entre as variáveis que compõem o perfil dos professores com a prática educativa com os alunos-idosos.

A investigação assume o caráter quantitativo quanto aos procedimentos de análise em relação aos fenômenos estudados, tendo em vista a natureza dos instrumentos que foram utilizados.

\section{Local de Investigação}

No início do segundo semestre de 2006, a Escola de Artes, Ciências e Humanidades da Universidade de São Paulo (EACH USP), implementou na Unidade a Universidade Aberta à Terceira Idade (UnATI). A UnATI EACH é um programa de educação permanente para atualização e aquisição de novos conhecimentos.

As atividades propostas são oferecidas através de 1. disciplinas regulares - vagas nos cursos de graduação da EACH USP (alguns docentes estabelecem como pré-requisito para a matrícula o ensino médio completo); 2. atividades didático-culturais e 3. atividades físico-esportivas. As atividades didático-culturais caracterizam-se pelo oferecimento de cursos, oficinas e palestras oriundas das seguintes áreas de conhecimento: Psicologia e Relações Sociais, Saúde e Qualidade de vida, Educação e Cidadania, Física e Corporal, Cultura, Atualidades e novas Tecnologias.

\section{Participantes}

A investigação contou com a participação de 82 professores e monitores envolvidos no período de nove semestres nas atividades da UnATI EACH USP. 


\section{Critérios de Inclusão}

Professores responsáveis por atividades e monitores graduandos do programa de educação permanente para idosos investigado, que voluntariamente participaram do estudo.

\section{Critérios de Exclusão}

Professores e monitores com menos de um semestre de trabalho no programa.

\section{Instrumentos}

O protocolo de pesquisa reúne duas seções distintas:

Primeira seção: Variáveis sociodemográficas e educativas: Dez itens que abordam: 1) Idade; 2) Sexo; 3) É professor responsável pela atividade da UnATI EACH?; 4) No caso dos docentes, qual a área do conhecimento de formação no ensino superior?; 5) Qual a titulação e a que curso está vinculado na universidade?; 6) Se monitor, qual curso e semestre está cursando?; 7) Quais atividade(s) que desenvolve na UnATI EACH?; 8) Desde quando oferece (ou é monitor de) atividades na UnATI EACH?; 9) Antes disso trabalhou com idosos?; 10) Atividades oferecidas e área de experiência de trabalho anterior com idosos.

Segunda seção: Estratégicas pedagógicas: Quatro itens que abordam: 1) identificação das metodologias de ensino realizada a partir da questão "Dentre as metodologia(s) utilizada(s) para ensinar o aluno idoso listadas abaixo, quais são utilizadas nas atividades que você desenvolve na UnATI EACH?" (1. aula expositiva, 2. discussão de textos com toda a sala, 3. discussão de textos em grupos, 4. dinâmica de grupo, 5 . dialógica professor-aluno, 6. grupo focal, 7. demonstração de movimentos físicos, 8. exercícios, 9. físico-esportivos, 10. expressão corporal, 11. debates, 12. outros). 2) Ordem de importância da atividade (de 1 a 12 dos doze itens apresentados). 3) Recursos didáticos: identificados a partir de uma listagem contendo (1. quadro/giz, 2. data-show, 3. DVD, 4. microcomputador, 5. textos impressos, 6. apostilas, 7. aparelho de som, 8. equipamentos/materiais técnicos para atividade física). 4) Percepções sobre estratégias necessárias à facilitação da aprendizagem do idoso identificadas a partir da seguinte questão aberta "Baseado na sua experiência como docente na UnATI, que estratégias facilitam a aprendizagem da pessoa idosa?".

\section{Procedimentos}

Foi realizada uma consulta aos registros do corpo docente da UnATI EACH referente ao período de sua implantação até o ano da aplicação da pesquisa (nove semestres letivos). Após a identificação dos

Educação \& Realidade, Porto Alegre, v. 40, n. 1, p. 81-103, jan./mar. 2015.

Disponível em: <http://www.ufrgs.br/edu_realidade> 
Metodologias e Estratégias Pedagógicas utilizadas por Educadores...

possíveis sujeitos, foi enviado um convite explicando os objetivos e os procedimentos do estudo, e uma solicitação para agendamento das entrevistas pelos pesquisadores para a coleta de dados. Todos os professores e monitores aceitaram prontamente os termos e colaboraram para a montagem dos horários de coleta.

Os professores e monitores foram informados sobre o caráter sigiloso, gratuito e voluntário de sua participação, o não oferecimento de riscos biopsicossociais à amostra estudada e a possibilidade de o participante abandonar a pesquisa, se assim desejar. Após a aceitação para a participação no estudo, todos os participantes assinaram o Termo de Consentimento Livre e Esclarecido (TCLE).

A entrevista de pesquisa foi conduzida por pesquisadores devidamente capacitados e treinados pela pesquisadora responsável pelo estudo. A duração da coleta de dados com cada participante foi em média de 30 minutos.

\section{Aspectos Éticos}

A pesquisa foi aprovada pelo Comitê de Ética em Pesquisa do Instituto de Psicologia da USP, sob o parecer número 2010.043.

\section{Análise dos Dados}

Para descrever o perfil da amostra, segundo as diversas variáveis em estudo, foram feitas tabelas de frequência das variáveis categóricas e estatísticas descritivas, como medidas de posição e dispersão, das variáveis contínuas.

As respostas à questão aberta sobre percepções foram categorizadas segundo o método de Análise de Conteúdo (Minayo, 2004) para gerar dados numéricos de frequência de respostas. Para identificar o agrupamento das respostas às questões, foi gerado um dendograma por intermédio do método de Ward (Hair et al., 2005).

Os dados foram digitados no Programa Epidata versão 3.1. Para análise estatística foram utilizados os programas computacionais SPSS v.17.0 e Statistica v. 7.0.

\section{Resultados}

A Tabela 1 apresenta as características sociodemográficas e de vínculo acadêmico da amostra estudada. Observa-se o predomínio de participantes do sexo feminino, tanto entre os discentes (monitores) quanto entre os professores responsáveis. 
Tabela 1 - Características Sociodemográficas e de Vínculo Acadêmico dos Participantes $(\mathrm{N}=82)$

\begin{tabular}{|c|c|c|c|c|c|c|}
\hline \multirow{3}{*}{ Variáveis } & \multicolumn{6}{|c|}{ Grupos } \\
\hline & \multicolumn{2}{|c|}{ Total } & \multicolumn{2}{|c|}{ Discentes } & \multicolumn{2}{|c|}{ Docentes } \\
\hline & $\mathrm{n}=82$ & $\%$ & $\mathrm{n}=57$ & $\%$ & $\mathrm{n}=25$ & $\%$ \\
\hline \multicolumn{7}{|l|}{ Sexo } \\
\hline Masculino & 13 & 15,85 & 6 & 10,53 & 7 & 28,00 \\
\hline Feminino & 69 & 84,15 & 51 & 89,47 & 18 & 72,00 \\
\hline \multicolumn{7}{|l|}{ Idade } \\
\hline Média (DP) & 28,46 & $(13,20)$ & 20,91 & $(2,92)$ & 45,68 & $(11,13)$ \\
\hline Mediana & \multicolumn{2}{|c|}{21,00} & \multicolumn{2}{|c|}{20,00} & \multicolumn{2}{|c|}{44,00} \\
\hline Mínimo - Máximo & 18,00 & 66,00 & 18,00 & 35,00 & 21,00 & 66,00 \\
\hline \multicolumn{7}{|l|}{$\begin{array}{l}\text { Vinculo acadêmico } \\
\text { com os cursos de } \\
\text { Graduação }\end{array}$} \\
\hline Gestão Ambiental & 2 & 2,44 & 0 & 0,00 & 2 & 8,00 \\
\hline $\begin{array}{l}\text { Ciências da } \\
\text { Atividade Física }\end{array}$ & 4 & 4,88 & 4 & 7,02 & 0 & 0,00 \\
\hline Gerontologia & 58 & 70,73 & 48 & 84,21 & 10 & 40,00 \\
\hline $\begin{array}{l}\text { Ciências da } \\
\text { Natureza }\end{array}$ & 1 & 1,22 & 0 & 0,00 & 1 & 4,00 \\
\hline Lazer e Turismo & 7 & 8,54 & 0 & 0,00 & 7 & 28,00 \\
\hline Obstetrícia & 2 & 2,44 & 0 & 0,00 & 2 & 8,00 \\
\hline Têxtil e Moda & 1 & 1,22 & 0 & 0,00 & 1 & 4,00 \\
\hline \multicolumn{7}{|l|}{ Discente (ano): } \\
\hline $1^{\circ}$ ano & -- & -- & 13 & 22,81 & -- & -- \\
\hline $2^{\circ}$ ano & -- & -- & 5 & 8,77 & -- & -- \\
\hline $3^{\circ}$ ano & -- & -- & 15 & 26,32 & -- & -- \\
\hline $4^{\circ}$ ano & -- & -- & 7 & 12,28 & -- & -- \\
\hline \multicolumn{7}{|l|}{ Docente (Área): } \\
\hline Ciências Biológicas & -- & -- & -- & -- & 9 & 36,00 \\
\hline Ciências Humanas & -- & -- & -- & -- & 8 & 32,00 \\
\hline Ciências Sociais & -- & -- & -- & -- & 4 & 16,00 \\
\hline Ciências Exatas & -- & -- & -- & -- & 1 & 4,00 \\
\hline $\begin{array}{l}\text { Ciências } \\
\text { Tecnológicas }\end{array}$ & -- & -- & -- & -- & 1 & 4,00 \\
\hline
\end{tabular}

Fonte: elaboração dos autores, com base no estudo Metodologias e Estratégias de Ensino, 2014.

A Tabela 2 traz as informações sobre as atividades que os professores e monitores desenvolvem na UNATI EACH e o autorrelato de experiência anterior no trabalho com o público idoso. 
Metodologias e Estratégias Pedagógicas utilizadas por Educadores...

Tabela 2 - Tipo de Atividade Realizada na UnATI EACH e Experiência Anterior de Trabalho com Idosos

\begin{tabular}{lcc}
\hline Categorias & $\mathrm{n}$ & $\%$ \\
\hline Atividade(s) que desenvolve na UnATI EACH & & \\
Disciplinas Regulares & 14 & 17,07 \\
Didático Cultural & 66 & 80,49 \\
Físico-Esportiva(s) & 6 & 7,32 \\
Palestras & 3 & 3,66 \\
Desde quando atua na UnATI EACH? & 7 & 8,54 \\
Há 5 anos & 1 & 1,22 \\
Há 4 anos & 11 & 13,42 \\
Há 3 anos & 21 & 25,61 \\
Há 2 anos & 42 & 51,22 \\
Há 1 ano & & \\
Antes disso trabalhou com idosos? & 54 & 65,85 \\
Não & 28 & 34,15 \\
Sim & & \\
\hline
\end{tabular}

Fonte: elaboração dos autores, com base no estudo Metodologias e Estratégias de Ensino, 2014.

A Tabela 3 apresenta as estratégias/metodologias classificadas pela amostra por ordem de importância na atividade educativa oferecida. Aquelas com menor média são as mais bem avaliadas. Aulas dialógicas professor-aluno como estratégia foi a mais indicada.

Na categoria outros foram emitidas estratégias/metodologias tais como, produção de vídeos, pesquisa na internet - atividade prática de laboratório, atividades práticas (receitas, elaboração de álbum, trabalhos manuais) e visitas a espaços de lazer e turísticos.

Tabela 3 - Estratégias/Metodologia(s) Utilizada(s) para Ensinar o Aluno Idoso por Ordem de Importância na Atividade Desenvolvida

\begin{tabular}{lccccc}
\hline Metodologia & Média & $\begin{array}{c}\text { Desvio- } \\
\text { padrão }\end{array}$ & Mínimo & Mediana & Máximo \\
\hline Dialógica professor- & 2,24 & 1,64 & 1,00 & 2,00 & 7,00 \\
aluno & 2,67 & 1,97 & 0,00 & 2,00 & 11,00 \\
Aula expositiva & 2,82 & 1,50 & 1,00 & 3,00 & 8,00 \\
Dinâmica de grupo & 3,31 & 1,75 & 0,00 & 3,00 & 7,00 \\
Discussão de textos & 3,38 & 2,21 & 0,00 & 3,00 & 11,00 \\
com toda a sala & 3,84 & 2,12 & 1,00 & 4,00 & 9,00 \\
Discussão de textos & 4,44 & 2,63 & 0,00 & 5,00 & 9,00 \\
Gruprupos focal & 5,00 & 2,62 & 0,00 & 5,00 & 10,00 \\
Expressão corporal & 5,57 & 3,28 & 0,00 & 6,00 & 10,00 \\
Demonstração de & movimentos físicos & 3,39 & 0,00 & 5,00 & 10,00 \\
Exercícios físico- & 5,70 & 3,47 & 0,00 & 1,50 & 11,00 \\
esportivos & 3,29 & Outras &
\end{tabular}

Fonte: elaboração dos autores, combase no estudo Metodologiase Estratégias deEnsino, 2014.

Os recursos didáticos utilizados para ensinar o aluno-idoso nas atividades desenvolvidas na UnATI EACH estão apresentados na Tabela 4. Dentre os recursos relatados, destacam-se o data-show, o microcomputador e textos impressos.

90 Educação \& Realidade, Porto Alegre, v. 40, n. 1, p. 81-103, jan./mar. 2015

Disponível em: <http://www.ufrgs.br/edu_realidade> 
Tabela 4 - Recursos Didáticos Utilizado(s) para Ensinar o AlunoIdoso nas Atividades Desenvolvidas na UnATI EACH

\begin{tabular}{lcc}
\hline Recursos & $\mathrm{n}$ & $\%$ \\
\hline Data-show & 61 & 74,39 \\
Microcomputador & 50 & 60,98 \\
Textos impressos & 48 & 58,54 \\
Aparelho de som & 28 & 34,15 \\
Apostilas & 27 & 32,93 \\
Quadro/giz & 24 & 29,27 \\
DVD & 23 & 28,05 \\
Equipamentos/materiais técnicos para atividade física & 8 & 9,76 \\
Outros & 10 & 12,20 \\
\hline
\end{tabular}

Fonte: elaboração dos autores, com base no estudo Metodologias eEstratégias deEnsino, 2014.

Além dos recursos citados anteriormente, foram mencionados materiais específicos para dinâmicas em grupo, mapas em papel, mapas digitais, utensílios de cozinha, livros, artigos da internet, indumentárias de dança e de teatro.

O levantamento sobre as percepções dos entrevistados sobre a facilitação da aprendizagem da pessoa idosa geraram categorias de respostas a partir da análise de seus conteúdos, como descritos na Tabela 5 .

Tabela 5 - Categorias e Emissões sobre o que Facilita a Aprendizagem da Pessoa Idosa

\begin{tabular}{|c|c|c|}
\hline Categorias & $\mathrm{n}(\%)$ & Exemplos de Emissões \\
\hline $\begin{array}{l}\text { Metodologia Participante } \\
\text { (troca de informações entre } \\
\text { professores/aprendizes) }\end{array}$ & $31(37,8)$ & $\begin{array}{l}\text { - O diálogo entre o professor e o } \\
\text { aluno. } \\
\text { - O contato e o diálogo entre o } \\
\text { professor e aluno. }\end{array}$ \\
\hline $\begin{array}{l}\text { Empatia/vínculo afetivo/ } \\
\text { atenção/paciência }\end{array}$ & $26(31,7)$ & $\begin{array}{l}\text { - Atenção individual, paciência e } \\
\text { calma na hora de explicar. } \\
\text { - Relação afetiva e compromisso. }\end{array}$ \\
\hline $\begin{array}{l}\text { Partir da experiência/interesse/ } \\
\text { demandas individuais dos } \\
\text { alunos }\end{array}$ & $24(29,3)$ & $\begin{array}{l}\text { - Partir daquilo que o idoso já tem } \\
\text { conhecimento. } \\
\text { - Didática direcionada a eles (os } \\
\text { idosos). }\end{array}$ \\
\hline Integração Teoria e Prática & $\begin{array}{c}13 \\
(15,85)\end{array}$ & $\begin{array}{l}\text { - O que facilita é a aula teórica } \\
\text { junto com a prática. }\end{array}$ \\
\hline $\begin{array}{l}\text { Exposição clara e objetiva do } \\
\text { assunto }\end{array}$ & $\begin{array}{c}13 \\
(15,85)\end{array}$ & $\begin{array}{l}\text { - Vocabulário claro, tom de voz } \\
\text { constante e alto. } \\
\text { - Clareza e objetividade. }\end{array}$ \\
\hline Dinâmicas de grupo & $10(12,2)$ & $\begin{array}{l}\text { - Acredito que a dinâmica de grupo } \\
\text { é uma ótima ferramenta de ensino. } \\
\text { - Aulas dinâmicas e com debates } \\
\text { entre os grupos. }\end{array}$ \\
\hline Repetir informações & $7(8,5)$ & $\begin{array}{l}\text { - Ações que reforcem a fixação, } \\
\text { como a repetição de atividades de } \\
\text { formas diferentes. }\end{array}$ \\
\hline
\end{tabular}

Educação \& Realidade, Porto Alegre, v. 40, n. 1, p. 81-103, jan./mar. 2015

Disponível em: <http://www.ufrgs.br/edu_realidade> 
Metodologias e Estratégias Pedagógicas utilizadas por Educadores...

Após calculo das frequências das categorias obtidas, estas foram agrupadas segundo o método de Ward. O objetivo desse método estatístico é classificar uma amostra de entidades (indivíduos ou objetos) em um pequeno número de grupos mutuamente excludentes, com base nas similaridades entre as entidades. Na análise, os grupos não são predefinidos, ao invés disso, a técnica é usada para identificar os grupos (Hair et al., 2005).

A análise de agrupamento geralmente envolve pelo menos três passos. O primeiro é a medida de alguma forma de similaridade ou associação entre as entidades para determinar quantos grupos realmente existem na amostra. O segundo é o próprio processo de agrupamento, nas quais entidades são particionadas em grupos (agrupamentos). O último passo é estabelecer o perfil das pessoas ou variáveis para determinar sua composição. Os resultados são representados por um dendograma, gráfico confeccionado por intermédio de um procedimento hierárquico, no qual cada objeto é colocado em um eixo e o outro eixo representa os passos no procedimento hierárquico. Começando com cada objeto representado como um agrupamento separado, o dendograma mostra graficamente como os agrupamentos são combinados em cada passo do procedimento até que todos estejam contidos em um único agrupamento (Hair et al., 2005).

De posse das categorias, a análise de agrupamentos, segundo o método de Ward, trouxe à tona três grupos de respostas referentes às categorias e emissões sobre o que facilita a aprendizagem da pessoa idosa, que estão representados na Figura 1.

Figura 1 - Dendograma obtido pelo Método de Ward para a Avaliação
das Respostas sobre o que Facilita a Aprendizagem da Pessoa Idosa

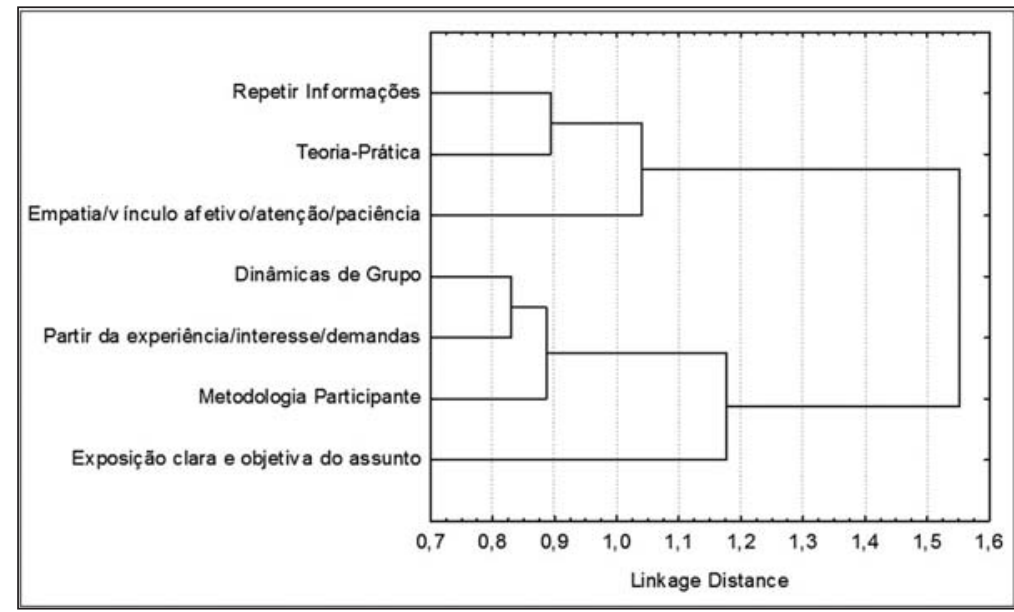

Fonte: elaboração dos autores, com base no estudo Metodologias e Estratégias de Ensino, 2014. 
Um primeiro agrupamento de respostas relacionadas à facilitação da aprendizagem do idoso relacionou as estratégias de repetir informações, unir teoria e prática, e a demonstração de empatia, vínculo afetivo, atenção e paciência. O segundo agrupamento foi formado pelas categorias de utilização de dinâmicas de grupo, as que envolvem partir da experiência, interesse e demandas individuais dos alunos, metodologias participativas. Por fim, a categoria exposição clara e objetiva do assunto compôs um grupo de respostas separado. Por meio da análise anterior foi possível a reelaboração das categorias anteriormente descritas, reduzindo-as a três categorias, conforme presentes na Tabela 6 .

Tabela 6 - Novas Categorias obtidas a partir do Dendograma obtido pelo Método de Ward sobre as Percepções dos Entrevistados

\begin{tabular}{|c|c|c|}
\hline Novas Categorias & $\mathrm{N}(\%)$ & Subcategorias \\
\hline $\begin{array}{l}\text { Categoria 1: Pedagogia } \\
\text { Participativa } \\
\text { problematizadora }\end{array}$ & $47(57,3)$ & $\begin{array}{l}\text { Dinâmicas de grupo. } \\
\text { Partir da experiência/interesse/ } \\
\text { demandas individuais dos alunos. } \\
\text { Troca de informações entre professores/ } \\
\text { aprendizes. }\end{array}$ \\
\hline $\begin{array}{l}\text { Categoria 2: } \\
\text { (Estratégias cognitivas } \\
\text { e habilidades } \\
\text { sociais empáticas } \\
\text { considerando os } \\
\text { declínios associados à } \\
\text { idade) }\end{array}$ & $39(47,6)$ & $\begin{array}{l}\text { Repetir informações } \\
\text { Unir Teoria e Prática } \\
\text { Empatia/vínculo afetivo/atenção/ } \\
\text { paciência }\end{array}$ \\
\hline $\begin{array}{l}\text { Categoria 3: Pedagogia } \\
\text { da Transmissão }\end{array}$ & $13(15,85)$ & Exposição clara e objetiva do assunto \\
\hline
\end{tabular}

Fonte: elaboração dos autores, com base no estudo Metodologias e Estratégias de Ensino, 2014.

\section{Discussão}

Educar o idoso para conhecer e acreditar em suas reais capacidades, desenvolver seus talentos, ensiná-lo a colocar o conhecimento a serviço de sua construção como sujeito, criar oportunidades para que aprenda a enfrentar obstáculos e preconceitos sociais, são ações que significam contribuir para promover a sua qualidade de vida e para o aprimoramento de sua cidadania. Vista dessa forma, a educação para adultos maduros e idosos apresenta-se como uma resposta inovadora aos novos desafios e demandas sociais gerados pela emergência de um novo grupo etário e de uma nova fase no curso de vida. Se pensada no contexto da educação ao longo de toda a vida, representa um instrumento promotor de mudança cultural.

Existem várias possibilidades de realização de programas abrangendo a educação não-formal, atividades visando ao lazer e à sociabilidade, mudança de atitudes e apoio psicossocial, dentre outras. No Brasil, esse campo expressa-se mais caracteristicamente em programas pertencentes à modalidade Universidade da Terceira Idade, normalmente funcionando como projetos de extensão universitária.

Educação \& Realidade, Porto Alegre, v. 40, n. 1, p. 81-103, jan./mar. 2015. 
Metodologias e Estratégias Pedagógicas utilizadas por Educadores...

Nesse contexto, pareceu-nos relevante conhecer o perfil de professores de diferentes origens educacionais e extratos etários, como também identificar as estratégias/metodologias de ensino e recursos didáticos utilizados.

Os resultados deste estudo, comparados com perfis de outras experiências de UnATIs relatadas na literatura, apresentam algumas semelhanças. Verificou-se a predominância de professoras $(84,15 \%)$, das áreas de ciências humanas e biológicas. A vasta maioria de professoras mulheres responsáveis pelas atividades é também descrita em estudos realizados por Cachioni (2002) e Pelloso-Lima (2001). Não é de causar estranheza porque o magistério, em todos os seus níveis, é uma profissão majoritariamente feminina, assim como a pesquisa na universidade tende a contar com a presença mais forte de mulheres.

Quanto à área de formação, são compatíveis com a natureza do currículo proposto. Possuem idade média de 28 anos, uma vez que a maior parte dos monitores são alunos concluintes dos cursos de graduação. Resultado semelhante foi verificado no programa para idosos da Universidade Federal de Santa Maria (RS), realizado por Cachioni (2002).

Os alunos da graduação, principalmente do curso de gerontologia, participam ativamente da construção das atividades junto com os professores responsáveis pelas oficinas, como também realizam pesquisas de iniciação científica e trabalhos de conclusão de curso. O convívio e a troca de saberes entre as diferentes gerações são percebidos como extremamente importantes para o desenvolvimento pessoal e profissional dos envolvidos no programa, conforme verificado por Cachioni e Aguilar (2008), em estudo realizado na UnATI EACH.

As atividades realizadas estão centralizadas na denominada didática-cultural. Trata-se de cursos, oficinas e palestras oriundas das seguintes áreas de conhecimento: Psicologia e Relações Sociais, Saúde e Qualidade de Vida, Educação e Cidadania, Física e Corporal, Cultura, Humanidades e Atualidades, com conteúdo descrito no Quadro 1 do presente estudo. As atividades realizadas nas disciplinas regulares representam $17,07 \%$ da amostra.

A UnATI EACH foi organizada conforme o modelo francês, idealizado pelo primeiro programa em Toulouse na França, com os desdobramentos posteriores realizados na Universidade de Nantèrre.

Na Universidade de Ciências Sociais de Toulouse os cursos eram regulares, com duração de um semestre a um ano. Incluíam-se também palestras debates, cursos de idiomas, expressão artística, caminhadas, esportes, viagens, passeios, mesas-redondas sobre temas de saúde, concertos, mostras de dança, eventos culturais abertos, debates sobre problemas da atualidade e reuniões literárias. Em outra vertente, na Universidade de Nantèrre, abriu-se a possibilidade dos idosos frequentarem as disciplinas oferecidas tradicionalmente a alunos de cur-

94 Educação \& Realidade, Porto Alegre, v. 40, n. 1, p. 81-103, jan./mar. 2015. Disponível em: <http://www.ufrgs.br/edu_realidade> 
so superior. Na mesma sala de aula, indivíduos com idades e formação acadêmica diversas relacionavam-se sem qualquer obstáculo, levando as pessoas a adquirirem mais segurança para discutir problemas intelectuais e para trocar ideias com a geração anterior; esse contato levou à valorização dos idosos pelos jovens (Attias-Donfut, 1979; Cachioni, 2002; Cachioni; Aguilar, 2008).

Sobre a experiência anterior de trabalho com pessoas idosas, segundo a maioria dos educadores, a UnATI é o primeiro campo de trabalho na área gerontológica. O mesmo dado foi verificado por Cachioni (2002) no estudo realizado com docentes de sete UnATIs brasileiras.

O investimento profissional na área gerontológica tem ocorrido por meio do trabalho nos próprios programas, onde a maioria tende a permanecer por um longo período, da participação em grupos de pesquisa e estudo e de leituras acerca de questões sobre a velhice. Os docentes mais comprometidos com a área são os pertencentes às instituições que oferecem a possibilidade de formação e especialização por intermédio de cursos e de núcleos de estudo e pesquisa, como ocorre na EACH.

A pesquisa de Lima (1999) também apresenta dados semelhantes aos coletados na presente investigação. A autora verificou que a maioria dos professores da UnATI da Universidade Estadual do Rio de Janeiro faz parte do quadro de docentes da universidade. A maior parte deles adquiriu sua experiência de trabalho com pessoas idosas na própria UnATI/UERJ. Iniciaram atividades em outros programas para a terceira idade após sua inserção na UnATI/UERJ. Participar das atividades do programa significa a possibilidade de convites para outros trabalhos e de fazer currículo.

Aulas dialógicas professor-aluno, seguida de aulas expositivas, e das dinâmicas de grupo, foram as estratégias/metodologias, com maiores emissões de respostas, utilizadas para ensinar o aluno idoso nas atividades desenvolvidas na UnATI EACH, entre os docentes entrevistados. Eles ainda consideram que a aula dialógica é a mais apropriada segundo as características das atividades e dos temas abordados. Esta posição pedagógica é confirmada por Palma (2000). Para a autora, os idosos não são aprendizes passivos, mas devem contribuir ativamente para o seu próprio aprendizado e, por extensão, para toda a sociedade. Durante o processo educacional, deve-se encorajar uma apropriação ativa e crítica, em vez do acúmulo estático de conhecimento por parte das pessoas idosas. Prova-se assim uma revisão na ideia de que a mudança é uma prerrogativa dos mais jovens. A necessidade de aprender é inerente ao processo de desenvolvimento, mas para cada estágio há um significado próprio, que se expressa de uma forma peculiar e pela busca de novos objetivos.

Dentre os recursos materiais utilizados nas atividades, destacam-se o data-show, o microcomputador e os textos impressos. As informa- 
Metodologias e Estratégias Pedagógicas utilizadas por Educadores...

ções apresentadas em slides e a reprodução de textos são recursos tradicionalmente utilizados nos cursos de graduação. O estudo realizado por Alves (1997) apontou que nem sempre a transposição do trabalho realizado com jovens alunos atendem as necessidades dos educandos idosos. No entanto, tais tecnologias de ensino são bem apreciadas pelos idosos, pois desejam ter as informações à disposição além do momento de sala de aula. Possuem também a oportunidade de armazenar e memorizar de maneira mais concreta os conhecimentos teóricos.

Um primeiro agrupamento de respostas relacionadas à facilitação da aprendizagem do idoso relacionou as estratégias de repetir informações, unir teoria e prática, e a demonstração de empatia, vínculo afetivo, atenção e paciência. O segundo agrupamento foi formado pelas categorias de utilização de dinâmicas de grupo, as que envolvem a partir da experiência, interesse e demandas individuais dos alunos, e metodologias participativas. Por fim, a categoria exposição clara e objetiva do assunto compôs um grupo de respostas separado. Por meio do método de Ward, foi possível reorganizar estas respostas em três categorias: Categoria 1. Pedagogia Participativa Problematizadora; Categoria 2. Estratégias cognitivas considerando os declínios associados à idade; Categoria 3. Pedagogia da Transmissão.

A Pedagogia da Problematização parte da base de que, em um mundo de mudanças rápidas, o importante não são os conhecimentos ou ideias nem os comportamentos corretos e fáceis que se espera, mas sim o aumento da capacidade do aluno - participante e agente da transformação social - para detectar os problemas reais e buscar para eles soluções originais e criativas (Bordenave, 1983).

A partir do uso dessa metodologia, podem ocorrer as seguintes consequências, que se manifestarão no âmbito individual e no âmbito grupal: no âmbito individual, o aluno será participante ativo, observador, formulando perguntas e expressando percepções e opiniões; será participante motivado pela percepção de problemas reais cuja solução se converta em reforço; sua aprendizagem será ligada a elementos significativos da realidade, com desenvolvimento das habilidades intelectuais de observação, análise, avaliação, compreensão e transferência; realizará intercâmbio e cooperação com os demais membros do grupo, que poderão se manifestar, por exemplo, na superação de conflitos. No âmbito grupal, os participantes serão conhecedores da realidade interna e externa da instituição; cooperarão na busca de soluções a problemas comuns; haverá redução da necessidade de um líder - os líderes serão situacionais; ocorrerá elevação do nível de desenvolvimento intelectual do grupo de participantes, graças a maior estimulação e desafio; aumentará a resistência à dominação.

A aplicação dessa metodologia em programas como os das Universidades da Terceira Idade permite ao docente uma reflexão mais crítica sobre o seu fazer pedagógico, favorece a mudança em sua ação e amplia suas possibilidades de intervenção consciente no ensino nessa

96 Educação \& Realidade, Porto Alegre, v. 40, n. 1, p. 81-103, jan./mar. 2015. Disponível em: <http://www.ufrgs.br/edu_realidade> 
área. Muitos desafios estão ainda por ser enfrentados na educação de idosos e na formação de professores para esse campo, mas alguns pressupostos já são confirmados através da prática. Há consenso, entre os teóricos e estudiosos que aqui apresentamos (Palma, 2000; Martinez, 1998; Clavijo, 1999; Saéz; Escabajal, 1998), de que a riqueza de experiências e conhecimentos acumulados deve fazer do aluno adulto maduro ou idoso o protagonista do processo de aprendizagem e do docente o mediador desse processo.

É na participação que se encontram a ocasião e a motivação para o desenvolvimento das potencialidades que convergem em uma dimensão socializadora, já que as possibilidades mais profundas do homem se inscrevem na realização de sua convivência com os demais. Por isso, graças à participação, observa-se - e se ouvem depoimentos a esse respeito - que o idoso recupera ou reafirma sua confiança em si mesmo e nos outros. Isso contribui para a sua qualidade de vida, pois, à medida que participa, encontra-se singularmente consigo mesmo e com os demais, revertendo esse fato em bem-estar.

Em relação à importância de apresentar estratégias cognitivas que considerem os declínios associados à idade, García (2009) elenca sete questões que devem ser consideradas: 1 . A experiência e a prática permitem a manutenção e a melhora de habilidades cognitivas. Relacionando teorias e conceitos, os idosos reconhecem o valor da experiência de aprendizagem no manejo e nas demandas da vida diária. 2. A motivação é um elemento fundamental para a participação de atividades educativas e estímulo das capacidades cognitivas em geral. Aprende-se melhor e mais depressa se houver interesse pelo assunto. Motivado, o idoso possui uma atitude ativa e empenhada no processo de aprendizagem e, por isso, aprende melhor. 3. Os diversos aspectos da biografia e personalidade de idosos influem no interesse pelas oportunidades e na competência demonstrada. 4. As atribuições e expectativas dos idosos em relação à própria capacidade intelectual. Sabe-se que uma atitude mais positiva melhora o rendimento intelectual. 5. A possibilidade do ser humano aprender novas informações é limitada: não é possível integrar grandes quantidades de informação ao mesmo tempo. É necessário selecionar as informações relevantes. 5. Quanto mais diversificadas forem as abordagens de um tema, quanto mais diferenciadas as tarefas, maior é a motivação e a concentração e melhor decorre a aprendizagem. 6. Estabelecimento claro das metas e objetivos da aprendizagem. Os idosos apreciam uma atividade ou um programa educacional que são organizados e possuem elementos claramente definidos. 7. Os conteúdos ensinados precisam ter significado e relevância para os idosos. Para tanto, os educadores precisam conhecer as reais necessidades educativas do educando idoso.

Autores como García (1998), Nicola (1999) e Cachioni (2002), verificaram em seus estudos que conhecer as características próprias dos idosos ajuda a melhorar as relações interpessoais, possibilita a compre- 
Metodologias e Estratégias Pedagógicas utilizadas por Educadores...

ensão de suas atitudes, permite explorar melhor seu potencial, favorece a integração e o crescimento; o diálogo se estabelece quando há uma relação horizontal, empática, em que todos se colocam como sujeitos do processo, passíveis de ensinar e de aprender; a valorização do idoso é fator preponderante para o estabelecimento de ações mais críticas, reflexivas e participativas. O afeto, o carinho, a consideração e a solidariedade dos professores favorecem sua aceitação no grupo e ajudam, significativamente, no desenvolvimento dos trabalhos e na elevação da autoestima dos idosos; os idosos, quando valorizados, são altamente produtivos e criativos; as pessoas mais aceitas aprendem a se autovalorizar e manifestam comportamentos que expressam felicidade, saúde mental e adequação social; as relações sociais tornam-se mais positivas quando o idoso passa a compreender a importância de sua experiência, vivendo plenamente as tarefas próprias de sua etapa vital.

Zabala (2001); Bordenave (1999), apresentam suas considerações em relação à pedagogia da transmissão. Palma (2001) afirma ser esta possibilidade metodológica a menos apropriada para o trabalho com os alunos idosos.

A Pedagogia de Transmissão pode ser caracterizada como aquela em que as ideias e conhecimentos são mais importantes na educação e o objetivo do aluno é de receber essas novas ideias e conhecimentos, feito uma página em branco, não desenvolvendo o crescimento pleno das pessoas e sua participação ativa no processo de mudanças e evolução. Sua metodologia acompanha a exposição oral do professor. O conteúdo é a verdade a ser absorvida pelo aluno, não estando relacionado ao cotidiano do aluno e muito menos às realidades sociais, mesmo quando se utiliza multimeios da moderna tecnologia educacional, avalia-se que esses veículos sofisticados não passam de mera transmissão (Zabala, 2001). Profissionais que adotam essa pedagogia têm dificuldades de utilizar outras formas de ensinar que não a de transmissão de conhecimentos. A pedagogia de transmissão quase sempre pode estar presente nas situações de educação não formal que, por sua vez, é uma entrega de conhecimentos sem o correspondente esforço para desenvolver as habilidades intelectuais (observação, análise, extrapolação e compreensão), conforme documentam Kretzer et al. (2010).

Bordenave (1999) sistematiza as repercussões da corrente pedagógica tradicional, incluindo um nível individual e outro social. No nível individual estão inseridos o hábito de tomar notas e memorizar; passividade do aluno e falta de atitude crítica; profundo respeito quanto as fontes de informação, sejam elas professores ou textos; distância entre teoria e prática; tendência ao racionalismo radical; preferência pela especulação teórica e falta de problematização da realidade.

No nível social incluem a adoção inadequada de informações científicas e tecnológicas de países desenvolvidos; adoção indiscriminada de modelos de pensamento elaborado em outras regiões (inadap- 
tação cultural); individualismo e falta de participação e cooperação e falta de conhecimento da própria realidade e, consequentemente, imitação de padrões intelectuais, artísticos e institucionais estrangeiros; submissão à dominação e ao colonialismo; manutenção da divisão de classes sociais (status quo).

Para Kretzer et al. (2010), pode-se observar que na tendência pedagógica tradicional, as ações de ensino estão centradas na exposição dos conhecimentos pelo educador. $\mathrm{O}$ educador assume funções como vigiar e aconselhar os educandos, corrigir e ensinar a matéria. É visto como a autoridade máxima, um organizador dos conteúdos e estratégias de ensino e, portanto, o único responsável e condutor do processo educativo. Há predominância da exposição oral dos conteúdos, seguindo uma sequência predeterminada e fixa, independentemente do contexto social; enfatiza-se a necessidade de repetições para garantir a memorização dos conteúdos. Os conteúdos e procedimentos didáticos não estão relacionados ao cotidiano do educando e muito menos às realidades sociais.

Segundo Palma (2001), na relação educador educando prevalece a autoridade do educador, exigindo uma atitude receptiva dos educandos e impedindo a comunicação entre eles. O educador transmite o conteúdo como uma verdade a ser absorvida. Os conteúdos correspondem aos conhecimentos e valores sociais acumulados pelas gerações passadas como verdades acabadas, e, embora o momento de ensino vise à preparação para a vida, não busca estabelecer relação entre os conteúdos que se ensinam e os interesses dos educandos idosos, tampouco entre esses e os problemas reais que afetam a sociedade.

Muitos desafios estão ainda por ser enfrentados na educação de idosos e na formação de professores para esse campo, mas alguns pressupostos já são confirmados através da prática realizada na UnATI EACH. Em suma, os dados aqui apresentados revelam que a riqueza de experiências e conhecimentos acumulados deve fazer do aluno adulto maduro ou idoso o protagonista do processo de aprendizagem e, do docente, o mediador desse processo.

\section{Considerações Finais}

O perfil dos professores/monitores da UnATI EACH USP destaca-se como um grupo jovem e estudioso da área gerontológica. Para os monitores, a participação nas atividades do programa conferiu a possibilidade de colocar em prática, por meio da intervenção, os conhecimentos adquiridos nos cursos de graduação. Para os professores oriundos dos diversos cursos de graduação, o programa possibilitou o envolvimento na extensão universitária e novas oportunidades de pesquisa.

A maior parte dos educadores encontraram na UnATI a primeira experiência de trabalho com pessoas idosas. De fato, o programa pode

Educação \& Realidade, Porto Alegre, v. 40, n. 1, p. 81-103, jan./mar. 2015

Disponível em: <http://www.ufrgs.br/edu_realidade> 
Metodologias e Estratégias Pedagógicas utilizadas por Educadores...

ser caracterizado como um laboratório-escola, principalmente aos estudantes do curso de bacharelado em gerontologia. Os monitores graduandos, futuros profissionais da área gerontológica, estão colhendo frutos importantes da relação estabelecida com os idosos - estão iniciando a construção de parte da trajetória de suas carreiras.

Parte significativa das atividades oferecidas pela UnATI EACH, denominadas didático-culturais, caracterizam-se por minicursos e oficinas com duração mínima de um semestre letivo. A metodologia utilizada baseia-se em aulas dialógicas nas quais professores e alunos-idosos trocam conhecimentos e experiências sobre os mais diversos assuntos. Ocorre uma interdependência por meio do ato de dar e receber informações. Existe um encontro intergeracional entre dois grupos de aprendizes, um que possui o saber técnico-científico e o outro com a experiência de toda uma vida. É um processo dinâmico, onde muitas vezes ocorrem trocas de papéis - educadores tornam-se aprendizes e aprendizes tornam-se educadores -, e ambos são beneficiados.

Em função dos conteúdos trabalhados nas atividades, os recursos didáticos mais utilizados são o data-show e o microcomputador. Cabe destacar que todas as salas destinadas ao programa são equipadas com os recursos de multimídias. Buscas de conteúdos na internet, tais como, sites, filmes, músicas, textos científicos, são possíveis com o computador à disposição. O data-show permite rápida visualização dos temas, que podem ser revistos ao longo das discussões, o que colabora para o melhor processamento da informação.

As metodologias utilizadas determinam o sucesso ou fracasso de uma atividade, bem como no desempenho intelectual do idoso. Sob essa perspectiva, os professores/monitores sugerem a pedagogia participativa problematizadora como arcabouço teórico para facilitar o aprendizado dos alunos-idosos. Durante o processo educacional, deve-se encorajar uma apropriação ativa e crítica, em vez do acúmulo estático de conhecimento por parte dos idosos. Os conteúdos discutidos precisam ter significado e relevância para os alunos.

As conclusões do presente estudo, aqui apresentadas, contribuem efetivamente para a importante área da gerontologia educacional, que visa dentre seus objetivos refletir sobre o processo de ensino-aprendizagem dos idosos.

Embora as UnATIs apresentem uma configuração privilegiada para diversas ações gerontológicas, há muito o que avançar nas discussões sobre os melhores métodos e práticas para o estabelecimento do processo de ensino.

Não é comum aos programas uma ampla discussão e divulgação sobre seus procedimentos pedagógicos, uma vez que o leque de atividades é extremamente diversificado. Nesse sentido, a presente pesquisa é pioneira. 
Sugere-se, para futuros estudos, a replicação da metodologia apresentada, investigando as questões de metodologias e estratégias pedagógicas sob o ponto de vista dos idosos, estudantes dos programas de educação permanente.

Recebido em 18 de março de 2014 Aprovado em 12 de novembro de 2014

\section{Referências}

ALVES, Gilda Glauce Martins. Universidade da Terceira Idade como Alternativa de Resgate da Cidadania Idosa: análise do caso da UNIMEP. Dissertação (Mestrado em Educação) - Universidade Metodista de Piracicaba, 1997.

ATTIAS DONFUT, Claudine. Seminários de Estudo sobre a Terceira Idade - 2a. parte. Cadernos da Terceira Idade, SESC, São Paulo, n. 3, p. 1-52, 1979.

BORDENAVE, Juan Díaz. Estratégias de Ensino-Aprendizagem. Revista Interamericana de Educação de Adultos, v. 3, n. 12, p. 7-21. Brasília, 1983.

BORDENAVE, Juan Díaz. Alguns Fatores Pedagógicos. In: SANTANA, José Paranaguá; CASTRO, Janete Lima (Org.). Capacitação em Desenvolvimento de Recursos Humanos CADRHU. Natal: Ministério da Saúde/Organização Pan-Americana da Saúde/Editora da UFRN, 1999. P. 261-268.

CACHIONI, Meire. Formação Profissional, Motivos e Crenças Relativas à Velhice e ao Desenvolvimento Pessoal entre Professores de Universidades da Terceira Idade. 2002. 276 f. Tese (Doutorado em Educação) - Faculdade de Educação, Universidade Estadual de Campinas, Campinas, 2002.

CACHIONI, Meire. Quem Educa os Idosos? Um estudo sobre professores de universidades da terceira idade. Alínea Editora: Campinas, 2003.

CACHIONI, Meire; ORDONEZ, Tiago Nascimento. Universidade da Terceira Idade. In: FREITAS, Elizabete Viana de; PY, Ligia (Org.). Tratado de Geriatria e Gerontologia. 3. ed. Rio de Janeiro: Guanabara Koogan, 2011, v. 1. P. 1655-1663.

CACHIONI, Meire; NERI, Anita Liberalesso. Educação e Velhice Bem-Sucedida no Contexto das Universidades da Terceira Idade. In: NERI, Anita Liberalesso; YASSUDA, Mônica Sanches; CACHIONI, Meire (Org.). Velhice Bem Sucedida. Aspectos afetivos e cognitivos. Campinas: Papirus, 2004. P. 46-69.

CACHIONI, Meire; PALMA, Lucia Terezinha Saccomori. A Educação Permanente: perspectiva para o trabalho com o adulto maduro e o idoso. In: FREITAS, Elizabete Viana de (Org.). Tratado de Geriatria e Gerontologia. 2. ed. Rio de Janeiro, 2006. P. 1456-1465

CACHIONI, Meire; AGUILAR, Luiz Enrique. A Convivência com Pessoas Idosas em Instituições de Ensino Superior: a percepção de alunos da graduação e funcionários. Revista Kairós Gerontologia, São Paulo, v. 11, p. 79-104, 2008.

CACHIONI, Meire; NERI, Anita Liberalesso. Motivos e Vantagens Associados ao Exercício da Docência em Universidades da Terceira Idade. Estudos Interdisciplinares sobre o Envelhecimento, Porto Alegre, v. 13, n. 1, p. 27-54, 2008.

CACHIONI, Meire. Universidade da Terceira Idade: história e pesquisa. Revista Kairós Gerontologia, São Paulo, v. 15, p. 01-08, 2012.

CLAVIJO, Manuel Velázquez. La Formación de Formadores para los Programas Universitarios de Mayores. Escuela Abierta, n. 3, p. 33-54, 1999. 
Metodologias e Estratégias Pedagógicas utilizadas por Educadores...

DE VITTA, Alberto. Bem-Estar Físico e Saúde Percebida: um estudo comparativo entre homens e mulheres adultos e idosos, sedentários e ativos. $125 \mathrm{f}$. Tese (Doutorado em Educação) - Faculdade de Educação, Universidade Estadual de Campinas, Campinas, 2001.

ESCARBAJAL, Andrés de Haro. Personas Mayores, Educación y Emancipación. In: LÓPEZ, Martinez de Miguel; ESCARBAJAL, Andrés de Haro. Alternativas Socioeducativas para las Personas Mayores. Madrid: Dykinson, 2009.

GARCÍA, Aretio Sanchez. El Educador Social ante la Actualidad y Necesidad de la Educación en los Mayores. In: MINGUEZ, Garcia; GARCIA, Aretio Sanchez (Org.). El Tabú de la Terminología. Un modelo de educación en los mayores: la interactividad. Dykinson: Madrid, 1998.

GARCÍA, Lourdes Bermejo. Gerontología Educativa: como diseñar proyectos educativos con personas mayores. Madrid: Panamericana, 2009.

GIL, Antonio Carlos. Métodos e Técnicas de Pesquisa Social. São Paulo: Atlas, 1999. GIUBILEI, Sônia. Uma Pedagogia para o Idoso. A Terceira Idade, Ano V, n. 7, p. 7-14, jun. 1993.

HAIR, Joseph F. et al. Multivariate Data Analysis. 5. ed. New Jersey: Pearson Education, 2005.

KRETZER, Fernanda Leal et al. Qualidade de Vida e Nível de Atividade Física de Indivíduos na Meia-idade Participantes de Projetos de Extensão Universitária. Revista Baiana de Saúde Pública, Salvador, v. 34, n. 1, p. 146-158, 2010.

LIMA, Marcelo Alves. A Gestão da Experiência de Envelhecer em um Programa para a Terceira Idade: a UnATI/UERJ. Dissertação (Mestrado em Antropologia Social) - Instituto de Filosofia e Ciências/IFCH, Universidade Estadual de Campinas, Campinas, 1999.

MARTINEZ, Mariano Sanchez. La Semántica de la Terminología en la Educación de los Mayores. La Gerontagogia. In: I JORNADA SOBRE PERSONAS MAYORES Y EDUCADORES SOCIALES. Anais... Grupo Editorial Universitario: 1998.

MINAYO, Maria Cecília de Souza. O Desafio do Conhecimento: pesquisa qualitativa em saúde. São Paulo: Hucitec, 2004.

NICOLA, Ivanila P. Formação de Recursos Humanos para uma Ação Educativa Gerontológica. Gerontologia, São Paulo, v. 7, n. 4, p. 178-191, 1999.

PALMA, Lucia Terezinha Saccomori. Educação Permanente e Qualidade de Vida. Indicativos para uma velhice bem-sucedida. Passo Fundo: UPF Editora, 2000.

PALMA, Lucia Terezinha Saccomori. Gerontogogia: Proposta Sócio-Educativa para Adultos Maduros e Idosos. Conferência apresentada. In: VII FÓRUM NACIONAL DE COORDENADORES DE PROJETOS DA TERCEIRA IDADE; VI ENCONTRO NACIONAL DE ESTUDANTES DA TERCEIRA IDADE DE INSTITUIÇÕES DE ENSINO SUPERIOR. São Luís, 21-23 out. 2001.

PELLOSO-LIMA, Mariúza. Gerontologia Educacional - uma pedagogia específica para o idoso. Uma nova concepção de velhice. São Paulo: Editora LTr, 2001. SÁEZ, Juan; ESCARBAJAL, Andrés. La Educación de Personas Adultas. En Defensa de la Reflexividad Crítica. Salamanca: Amarú Ediciones, 1998.

SWINDELL, Rachel. Educational Initiatives for Older Learners. Education Resources Information Center. 2009. P. 01-21.

ZABALA, Antoni. Concepção da Aprendizagem e Enfoque Globalizador. In: ZABALA Antoni. Enfoque Globalizador e Pensamento Complexo. Porto Alegre: ArtMed, 2001. P. 89-136.

102 Educação \& Realidade, Porto Alegre, v. 40, n. 1, p. 81-103, jan./mar. 2015 Disponível em: <http://www.ufrgs.br/edu_realidade> 
Meire Cachionié docente do Curso de Bacharelado em Gerontologia da Escola de Artes, Ciências e Humanidades da Universidade de São Paulo (USP). E-mail:meirec@usp.br

Tiago Nascimento Ordonezé bacharel em Gerontologia da Escola de Artes, Ciências e Humanidades da Universidade de São Paulo.

E-mail: tiago.ordonez@saocaetanodosul.sp.gov.br

Samila Sathler Tavares Batistoni é docente do Curso de Bacharelado em Gerontologia da Escola de Artes, Ciências e Humanidades da Universidade de São Paulo (USP).

E-mail: samilabatistoni@usp.br

Thaís Bento Lima-Silva é doutoranda em Neurologia pela Faculdade de Medicina da Universidade de São Paulo (USP).

E-mail: gerontologathais@gmail.com 